\title{
A Case of Mild Hyperparathyroidism in Childhood
}

\author{
S. C. LATHAM ${ }^{\star}$, Ph. BORDIER, F. H. DOYLE, F. D. HIGGS, G. F. JOPLIN, \\ SELWYN TAYLOR, and N. C. THALASSINOS \\ From the Royal Postgraduate Medical School, Hammersmith Hospital, London W.12; and \\ Le Centre du Métabolisme Phosphocalcique, Hôpital Lariboisière, Paris $10^{e}$
}

Hypercalcaemia is rare in childhood, but when present it can lead to impairment of renal function, to disturbances of growth and intellect, and, on rare occasions, to death. Investigations leading to its unveiling are usually not undertaken until the child has developed long-term complications.

In children the most common cause of hypercalcaemia is vitamin D intoxication, but this must be differentiated from the idiopathic hypercalcaemia of infancy, hyperparathyroidism, and in older children from the hypercalcaemia of sarcoidosis. Difficulties may arise as there is a scarcity of normal childhood data for the investigation of calcium metabolism, and an understandable hesitancy in exploring a child's neck if hyperparathyroidism is suspected.

This paper describes the steps in the diagnosis of hyperparathyroidism in a 9-year-old girl who remained under observation for 18 months before parathyroidectomy. She had no clear radiological signs of hyperparathyroidism, the serum calcium was only moderately raised, and there was no evidence of renal involvement.

\section{Case Report}

D. de G., a West Indian girl, first complained of severe constipation and abdominal pain at the time of her ninth birthday. The pain was an indefinite colic and resolved within 2 weeks, though her constipation persisted for a further 6 months. A little later she began to vomit after meals, but her appetite was unimpaired. She was sick as often as five times a week, but within 6 months this had subsided. The unusual nature and the severity of her constipation prompted the initial serum calcium estimation. All her symptoms resolved without treatment, she had normal bowel movements, and felt quite well during the months immediately before the exploration of her neck.

Her mother was in the habit of giving her three sisters and herself one teaspoonful of cod liver oil (approximately 500 i.u. of vitamin D) each day, and occasionally they were also given a teaspoonful of an

\footnotetext{
Received February 6, 1969.

^ Present address: University of Queensland, St. Lucia, Brisbane 4067, Australia.
}

emulsion containing $40 \%$ cod liver oil. Both preparations were stopped 3 months after the onset of her symptoms. Her parents and sisters were well and showed no biochemical abnormality.

Physical examination. She remained an alert and happy child. Her height remained on the 75th centile during the period of observation, but her weight fluctuated erratically between the 75 th and 90 th centile during the period of severe constipation. She was normotensive and showed no corneal calcification. The WISC full scale IQ was 75 before operation.

$\mathrm{Hb} 12.0$ g./100 ml.; WBC 4000/cu.mm.; electrolytes normal; the mean blood urea was $28 \mathrm{mg}$. $/ 100 \mathrm{ml}$., and the highest of 14 values was $38 \mathrm{mg}$. $/ 100 \mathrm{ml}$; s serum uric acid was $4.0 \mathrm{mg}$. $/ 100 \mathrm{ml}$.; serum cholesterol varied between 185 and $260 \mathrm{mg}$. $/ 100 \mathrm{ml}$.

Water concentration test: concentration to s.g. 1.022. ECG: normal; EEG: increase in the intermediate slow activity, with occasional runs of intermediate slow activity in the frontal region.

Thyroid, pituitary, and adrenal function were investigated and found to be normal.

Calcium metabolism. The sustained mild hypercalcaemia, low phosphate, and high urine calcium during the 18-month period of observation are shown in Table I.

The range of 22 plasma calcium estimations during a period of 18 months was $11-13.6 \mathrm{mg} . / 100 \mathrm{ml}$.; mean $12.4 \mathrm{mg} . / 100 \mathrm{ml}$.

The heat stable fraction of the alkaline phosphatase was $7 \%$, indicating that the majority was of bone origin. A hydrocortisone suppression test was carried out when she was $9 \frac{1}{2}$ years old and again when she was $10 \frac{1}{2}$, giving the full adult dose of hydrocortisone $40 \mathrm{mg}$. 8-hourly for 10 days (Table II). The first test showed a clear fall in the plasma calcium, and identical values were found in duplicate samples estimated in another hospital. The second test showed only a partial fall, when the plasma calcium was corrected to correspond with the change in the specific gravity of plasma.

The basal phosphate excretion index (PEI) values were high, the upper limit of normal for that age being -0.08 (Thalassinos, Latham, and Leese, 1969, unpublished observations). The PEI at $92 / 12,+0.07$; 9 6/12, +0.07; 9 7/12, +0.14; 9 9/12, +0.02; $911 / 12,+0 \cdot 14 ; 106 / 12,+0.03$. 
TABLE I

Plasma Biochemistry During 18 Months' Observation

\begin{tabular}{|c|c|c|c|c|c|c|}
\hline Age (yr.) & $\begin{array}{c}\text { Total Plasma } \\
\text { Proteins }(\mathrm{g} . / 100 \mathrm{ml} .)\end{array}$ & $\begin{array}{l}\text { Calcium } \\
(\mathrm{mg} . / 100 \mathrm{ml} . \\
\text { plasma) }\end{array}$ & $\begin{array}{l}\text { Magnesium } \\
(\mathrm{mg} / 100 \mathrm{ml} . \\
\text { plasma) }\end{array}$ & $\begin{array}{l}\text { Phosphate } \\
\text { (mg./100 ml. } \\
\text { plasma) }\end{array}$ & $\begin{array}{l}\text { Alk. Phos. } \\
\text { (KA Units) }\end{array}$ & $\begin{array}{l}\text { Urine Calcium } \\
\text { (mg./24 hr.) }\end{array}$ \\
\hline $\begin{array}{c}\text { Normal } \\
\text { range } \\
9 \frac{1}{4} \\
9 \frac{3}{4} \\
10 \frac{1}{2} \\
10 \frac{8}{4}\end{array}$ & $\begin{array}{c}5 \cdot 7-7 \cdot 9 \\
7 \cdot 2 \\
6 \cdot 7 \\
6 \cdot 8 \\
6 \cdot 1\end{array}$ & $\begin{array}{c}9 \cdot 0-11 \cdot 0 \\
12 \cdot 4 \\
12 \cdot 8 \\
12 \cdot 0 \\
12 \cdot 4\end{array}$ & $\begin{array}{c}1 \cdot 8-3 \cdot 6 \\
1 \cdot 8 \\
2 \cdot 0 \\
2 \cdot 1 \\
1 \cdot 9\end{array}$ & $\begin{array}{c}3 \cdot 5-4 \cdot 5 \\
3 \cdot 3 \\
3 \cdot 5 \\
2 \cdot 8 \\
3 \cdot 0\end{array}$ & $\begin{array}{c}15-30 \\
30 \\
28 \\
32 \\
30\end{array}$ & $\begin{array}{c}70-140 \\
394 \\
448 \\
- \\
244\end{array}$ \\
\hline
\end{tabular}

TABLE II

Hydrocortisone Suppression Test

\begin{tabular}{|c|c|c|c|c|}
\hline \multirow{2}{*}{ Day } & \multicolumn{2}{|c|}{ Aged $9 \frac{1}{2}$ years } & \multicolumn{2}{|c|}{ Aged $10 \frac{1}{2}$ years } \\
\hline & SG of Plasma & Calcium (mg./100 ml. plasma) & SG of Plasma & Calcium (mg./100 ml. plasma) \\
\hline $\begin{array}{r}0 \\
5 \\
10\end{array}$ & $\frac{1 \cdot 024-5}{1 \cdot 025-6}$ & $\begin{array}{l}11 \cdot 8 \\
11 \cdot 0 \\
10 \cdot 1\end{array}$ & $\begin{array}{l}1 \cdot 028 \\
1 \cdot 026 \\
1 \cdot 026\end{array}$ & $\begin{array}{l}13 \cdot 4 \\
12 \cdot 2 \\
12 \cdot 0\end{array}$ \\
\hline
\end{tabular}

Radiology. (i) Skeletal survey. The skeletal features of hypervitaminosis D or of idiopathic hypercalcaemia were not present. The radiological hallmark of hyperparathyroidism in the adult, subperiosteal cortical bone resorption in the middle phalanges of the hand, was not evident. The common childhood feature of metaphysial sclerosis was also not apparent (see Fig. 1). The cortex adjacent to the distal radial and ulnar metaphyses was, however, poorly defined, and the spongiosa in the metaphyses was plentiful. These findings favoured hyperparathyroidism as the cause of the hypercalcaemia, but did not exclude sarcoidosis. Two features are not uncommon in hyperparathyroidism: firstly, a reduction in the mineral density of cortical bone due to an increase in resorption cavities within the cortex, and secondly, an increased amount of trabecular or woven bone in the metaphysis. Both these features were shown in our patient by the following method.

(ii) Quantitative radiological findings. The bone mineral in the distal $8 \mathrm{~cm}$. of the left ulna was measured (Doyle, 1961). The average density of the cortical bone at 6,7 , and $8 \mathrm{~cm}$. from the distal end was low, $0.94 \mathrm{mg} / \mathrm{mm}^{3}$ (mean value in age-group $15-19=$ $1 \cdot 18 ; S D=0 \cdot 11)$. The ratio of the mineral thickness at $1 \mathrm{~cm}$. to that at $8 \mathrm{~cm}$., being a measure of the proportion of trabecular to cortical bone, was high, $57 \%$ (mean in age-group $15-19=31 \% ; S D=6 \%$ ). This high ratio is common in secondary hyperparathyroidism, and is an occasional finding in primary hyperparathyroidism in adults (Doyle, 1966). Though control data are not available for the age-group of this child, the quantitative findings strongly suggested the diagnosis of hyperparathyroidism.

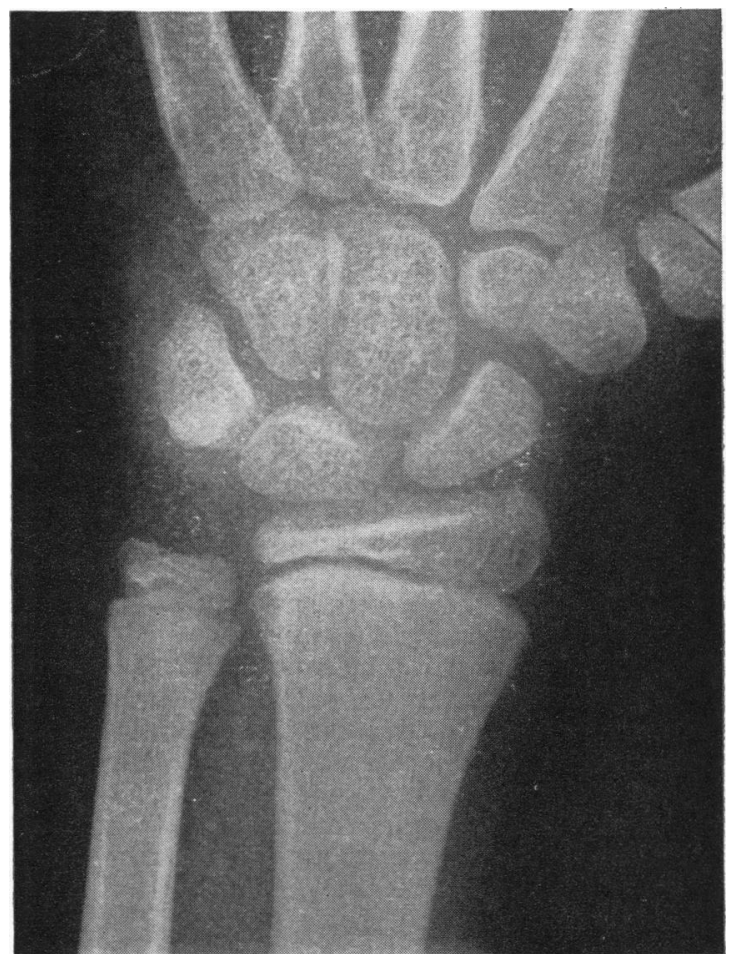

FIG. 1.-X-ray of left wrist at age $9 \frac{1}{2}$ years. The cortex adjacent to the inferior radial and ulnar metaphyses is poorly defined, but there is no feature to suggest hypervitaminosis $D$. 

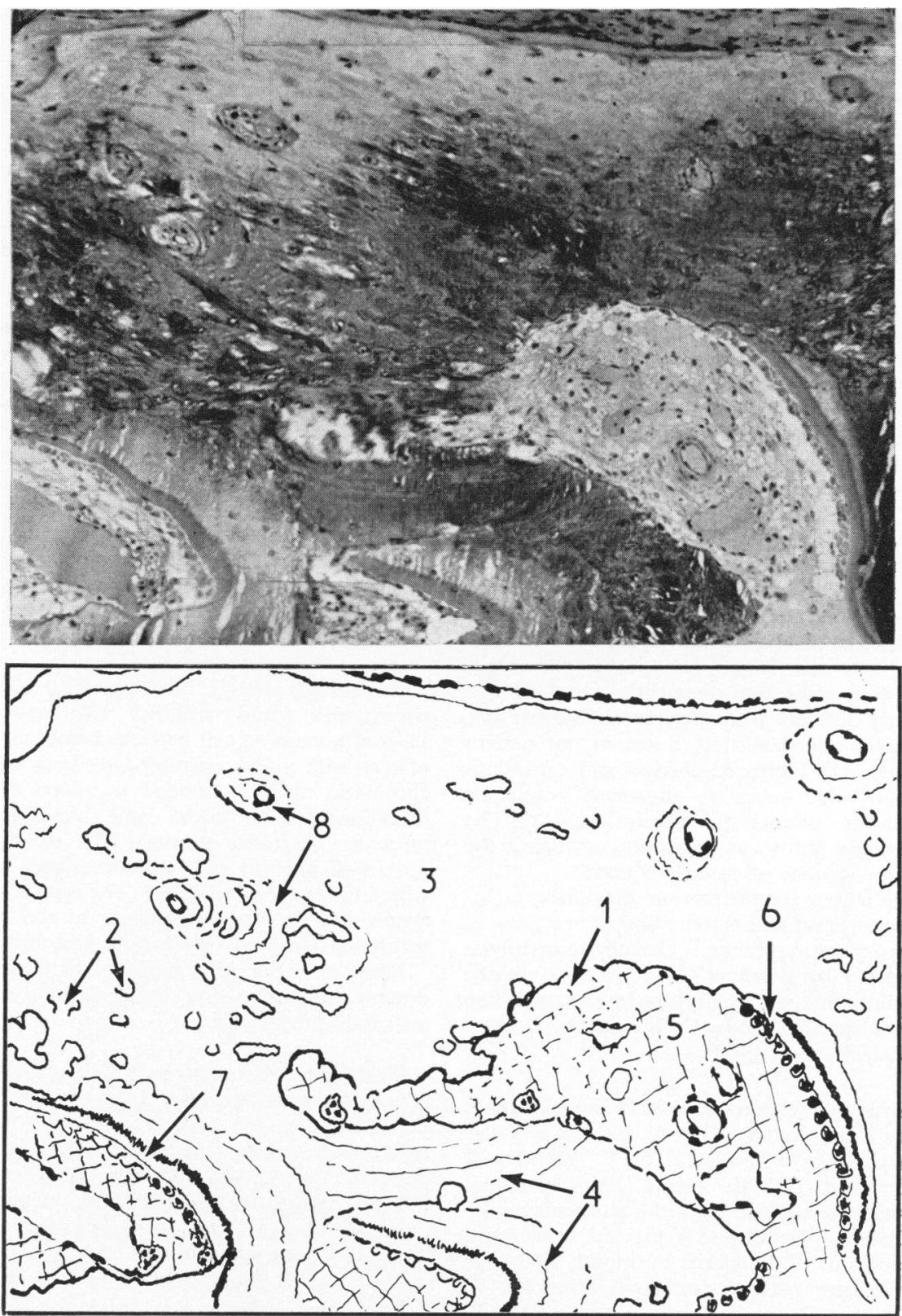

FIG. 2.-Undecalcified thin section of ilium, stained with toluidine blue. $(\times 430$.

1-Cavity produced in primary bone by osteoclastic resorption; 2-osteocytic osteolysis; 3-primary bone; 4-lamellar bone; 5-fibrous tissue filling the cavities; 6-osteoblasts adjacent to an osteoid seam; 7-calcification front; 8-Haversian systems.

Bone histology. A bone biopsy was taken to assist in making a firm diagnosis of hyperparathyroidism. An iliac crest biopsy was fixed in phosphate buffered formalin and embedded in a polyester resin without decalcification (Matrajt et al., 1967). $6 \mu$ sections were cut and stained with toluidine blue (see Fig. 2).

(i) Cortical bone. The outer part of the cortex, mainly composed of woven bone, showed evidence of resorption by osteocytic osteolysis and was covered by 
a thin layer of lamellar bone. In the inner part of the cortex the primary cortical bone had been replaced by Haversian lamellar systems, though a remnant of woven bone was still seen between the osteons. Large cavities, produced by osteoclastic resorption, were filled by fibrous tissue but few osteoclasts were seen. Some of these cavities were lined with one to three lamellae of new bone. The most recent lamellae consisted of osteoid, with very young and active osteoblasts. Osteocytic osteolysis was frequent.

(ii) Cancellous bone. Little woven bone remained. This was surrounded by lamellar bone in which osteocytic osteolysis was increased. Many Howships lacunae were shown along the margins of the trabeculae. These were filled with fibrous marrow, but osteoclasts were rare. The trabecular margins were covered with osteoid 1 to 3 lamellae in thickness; a calcification front was present and many active osteoblasts were seen.

(iii) Quantitative histology. The striking feature was the high percentage of osteocytes surrounded by osteolysis. This was $17 \cdot 5 \%$, compared with $3 \%$ as the upper normal limit in adults, and $6.6 \%$ from a biopsy taken at necropsy from a girl of 11 who had died from a cerebral haemorrhage. On the other hand, the percentage bone surface with osteoclastic resorption was $27 \cdot 2 \%$, being not clearly different from $22 \%$ in the normal girl.

Thus the main abnormalities shown in our patient were as follows. (1) Increased cortical and cancellous bone resorption, due more to increased osteocytic osteolysis than to osteoclastic resorption. (2) The presence of osteitis fibrosa in resorption cavities in the cortex and in the lacunae of cancellous bone.

The findings added support to our diagnosis, as increased bone resorption and osteitis fibrosa are classical features of hyperparathyroidism. Osteocytic osteolysis had been reported by Bélanger (1965) to be a specific effect of parathormone administration in rats, and also appears to be a specific feature in human hyperparathyroidism (Matrajt et al., 1968).

Investigations to exclude vitamin $D$ intoxication. Plasma vitamin D-like activity (Dr. G. Neale): 0.5-1 0 i.u./ml. (normal range 0.5-3.0 i.u./ml.). Vitamin D hypersensitivity test (C. E. Dent, 1968, personal communication): the plasma calcium, inorganic phosphate, and alkaline phosphatase remained unchanged following 10,000 i.u. of calciferol by mouth daily for 10 days; the urinary calcium increased from 400 to $600 \mathrm{mg} . / 24$ hours.

Investigations to exclude sarcoidosis. The Mantoux test $1 / 100$ and Kveim test were both negative. Tomograms of the lung hila and liver biopsy were both normal. BCG produced a normal 'take', and after this the Mantoux reaction became positive.

No suppression of the plasma calcium occurred when cortisone acetate $10 \mathrm{mg}$. t.d.s. was given for 2 weeks as a therapeutic trial when sarcoidosis was thought to be the probable diagnosis; the hypercalcaemia of these patients is readily suppressed by very small doses of cortisone (Anderson et al., 1954).

Conclusions. On the evidence available it was felt that the hypercalcaemia was neither due to vitamin D hypersensitivity nor to vitamin D intoxication. Sarcoidosis was excluded as far as was possible, and idiopathic hypercalcaemia was unlikely at this age as it is normally confined to infants. Moreover, the radiological appearances did not favour these diagnoses and the hypercalcaemia was only partly suppressed by hydrocortisone on the second occasion. The phosphate excretion index (PEI) was raised, indicating an increased parathyroid hormone secretion. Hyperparathyroidism therefore seemed the only likely cause, and in view of the very high urinary calcium which sooner or later would lead to renal complications, operation was advised.

Operation. The thyroid gland appeared normal. All four parathyroid glands were exposed. The right lower contained a small adenoma, and was removed in toto. Biopsies were taken of the remaining parathyroids, the thymus, and a large pad of brown fat which lay just above it.

Pathology (Dr. R. S. Whittaker). The right lower parathyroid gland weighed $100 \mathrm{mg}$. The tumour showed a variable cell pattern, being composed mainly of cells with a dark staining cytoplasm and large hyperchromatic nuclei, arranged in sheets and trabeculae. Occasional giant nuclei and binucleate cells were present. Scattered throught the tumour were small groups of oxyphil cells and occasional groups of cells with a very pale cytoplasm. The remaining parathyroid tissue was in marked contrast to the tumour, being composed of small chief cells and infiltrated by fat.

Biopsies of the other parathyroid glands also showed evidence of suppression, being composed of small chief cells infiltrated by fat.

Post-operative course. The plasma calcium had fallen to normal within 6 hours of operation and has remained so. No change occurred in the plasma magnesium or uric acid levels. 3 weeks later after her discharge the plasma values were: total proteins $6.8 \mathrm{mg}$./ $100 \mathrm{ml}$., calcium $10.2 \mathrm{mg} . / 100 \mathrm{ml}$., inorganic phosphate $5.2 \mathrm{mg} . / 100 \mathrm{ml}$., alkaline phosphatase $26 \mathrm{~K}-\mathrm{A}$ units. The urine calcium was now $56 \mathrm{mg} .24 \mathrm{hr}$. on a free diet, and the PEI had fallen to $-0 \cdot 12$ (normal).

\section{Discussion}

In 1930 Pemberton and Geddie reported the first case of hyperparathyroidism in a child, and there are now descriptions of 39 children under the age of 16 who have been found to have parathyroid adenoma (Nolan, Hayles, and Woolner, 1960; Fanconi and Mieth, 1967).

Among these there was overt evidence of bone disease in 29, renal stones in 11 but no case of 
nephrocalcinosis, whereas in the adult it is the renal manifestations that predominate (Fanconi and Mieth, 1967). To our knowledge there is only one other description of a child who had moderate hypercalcaemia and neither classical radiological bone disease nor renal involvement; a boy of $15 \frac{1}{2}$ found to be hypertensive at routine examination and subsequently to have a serum calcium of $13 \mathrm{mg} . / 100 \mathrm{ml}$. (Chaves-Carballo and Hayles, 1966).

There are also 10 descriptions of primary parathyroid hyperplasia, but all have occurred in children under the age of $2 \frac{1}{2}$ years, with the one exception of an 11-year-old girl recorded by Geldof (1967).

In the girl we describe, the oral hydrocortisone test (Dent, 1956; Dent and Watson, 1968) suppressed the hypercalcaemia to normal levels at the age of $9 \frac{1}{2}$ years, but on the second occasion at the age of $10 \frac{1}{2}$ years, failed to do so, the hypercalcaemia being only partially suppressed. Similarly, when she was treated with $30 \mathrm{mg}$. cortisone acetate daily there was no fall in the serum calcium level. We cannot explain the impressive suppression of the hypercalcaemia after the first course of hydrocortisone, but even in adults the failure of steroids to suppress the hypercalcaemia of hyperparathyroidism is not invariable (Gordan, 1960; Dent, 1962; Gwinup and Sayle, 1961; and Dent and Watson, 1968).

After excluding other causes of hypercalcaemia, we looked at other parameters which have been used in adults for detecting hyperparathyroidism, but have not been applied to children. The phosphate excretion index of Nordin and Fraser (1960) proved to be useful, but it was first necessary to establish a range of normal values for children, as these fall below the normal adult range (Thalassinos et al., 1969, unpublished observations). The values for the child that we describe were clearly raised before operation and fell to the normal range for her age after removal of the adenoma.

Radiology is often helpful, and skeletal changes have been found in $75 \%$ of the children described as having parathyroid adenoma. Metaphysial sclerosis due to an increased amount of spongiosa seems particularly common in children with hyperparathyroidism (Fanconi and Mieth, 1967). The high proportion of trabecular to cortical bone in this child's ulna is a reflection of the same feature, but it was not severe enough in her for a diagnosis to be based on routine radiography.

In adults quantitative bone histology is often abnormal in hyperparathyroidism in the absence of overt radiological abnormality. Riggs et al. (1965) showed a much increased osteoclastic resorption of cortical bone in patients who were radiologically normal. Recently Matrajt et al. (1968) have reported 4 patients with hyperparathyroidism in whom osteoclastic resorption was within normal limits but osteocytic osteolysis was much increased. The latter may prove to be one of the most sensitive histological parameters of increased circulating parathyroid hormone. It was a marked feature in our patient.

This child was extensively investigated in order to establish a diagnosis, as it was felt that her massive hypercalcuria would eventually lead to complications in the renal tract. An opportunity was perhaps lost for carrying out a longitudinal study of the effects of hypercalcaemia on the IQ, but serial EEG's did show the development of minor abnormalities just before operation and similar to the changes seen in adult hypercalcaemia (E. Allen and F. R. Singer, 1968, personal communication). Our estimate of the IQ was possibly falsely low, as she was unwell at the time, but since her operation she has regained her place among her age-group at school, though she had missed a considerable amount of schooling on account of her hospital admissions.

\section{Summary}

A West Indian girl aged 9 developed transient abdominal pain, vomiting, intense constipation, and occasional headaches. There was gross hypercalciuria and moderate hypercalcaemia which was suppressed to normal limits by oral hydrocortisone on the first occasion. A small parathyroid adenoma was subsequently removed, after which the plasma calcium reverted to normal and the hypercalciuria resolved. The phosphate excretion index, bone biopsy, and measurement of radiological bone density proved to be the most useful investigations in establishing a diagnosis.

We wish to thank Professor J. P. M. Tizard for his encouragement and permission to report this case, Professor C. E. Dent for his advice and for measuring the heat stable alkaline phosphatase, and Sirinn TunChot for his part in the assessment of the quantitative bone histology.

\section{REFERENCES}

Anderson, J., Dent, C. E., Harper, C., and Philpot, G. R. (1954) Effect of cortisone on calcium metabolism in sarcoidosis with hypercalcaemia. Possibly antagonistic actions of cortisone and vitamin D. Lancet, 2, 720.

Bélanger, L. F. (1965). Osteolysis: an outlook on its mechanism and causation. In The Parathyroid Glands, pp. 137-143. Ed. by P. J. Gaillard, R. V. Talmage, and A. M. Budy. University of Chicago Press, Chicago. 
Chaves-Carballo, E., and Hayles, A. B. (1966). Parathyroid adenoma in children. Amer. F. Dis. Child., 112, 553.

Dent, C. E. (1956). Cortisone test for hyperparathyroidism. Brit. med. f., 1, 230.

- (1962). Some problems of hyperparathyroidism. ibid., 2, 1419 and 1495.

- and Watson, L. (1968). The hydrocortisone test in primary and tertiary hyperparathyroidism. Lancet, 2, 662.

Doyle, F. H. (1961). Ulnar mineral concentration in metabolic bone diseases. Brit. F. Radiol., 34, 698.

- (1966). Some quantitative radiological observations in primary and secondary hyperparathyroidism. ibid, 39, 161.

Fanconi, A., and Mieth, D. (1967). Primärer Hyperparathyreoidismus bei einem 12jährigen Knaben. Helv. paediat. Acta, 22, 160.

Geldof, W. C. (1967). An eleven year old girl with hyperparathyroidism. Ned. T. Geneesk, 111, 1156.

Gordan, G. S. (1960). Current status of laboratory tests for hyperparathyroidism. Acta endocr.'(Kbh.), 35, suppl. 51, 463.
Gwinup, G., and Sayle, B. (1961). Cortisone responsive hypercalcaemia in proved hyperparathyroidism. Ann. intern. Med., $55,1001$.

Matrajt, H., Bordier, Ph., Martin, J., and Hioco, D. (1967). Technique pour l'inclusion des biopsies osseuses non decalcifiées. 7. Microscopie, 6, 499.

- - Tun-Chot, S., and Hioco, D. (1968). Lesions osseuses de l'hyperparathyroidisme. In L'Actualite Rhumatologique. pp. 283-285. Ed. by S. de Seze. Expansion Scientifique.

Nolan, R. B., Hayles, A. B., and Woolner, L. B. (1960). Adenoma of the parathyroid gland in children. Amer. F. Dis. Child., 99,622 .

Nordin, B. E. C., and Fraser, R. (1960). Assessment of urinary phosphate excretion. Lancet, 1, 947.

Pemberton, J. de J., and Geddie, K. B. (1930). Hyperparathyroidism. Ann. Surg., 92, 202.

Riggs, B. K. L., Kelly, P. J., Jowsey, J., and Keating, F. R., Jr. (1965). Skeletal alterations in hyperparathyroidism: determination of bone formation, resorption and morphologic changes by microradiography. f. clin. Endocr., 25, 777. 